\title{
Trichomoniasis and Lactoferrin: Future Prospects
}

\author{
Rakesh Sehgal, ${ }^{1}$ Kapil Goyal, ${ }^{1}$ and Alka Sehgal ${ }^{2}$ \\ ${ }^{1}$ Department of Parasitology, Postgraduate Institute of Medical Education and Research, Chandigarh 160012, India \\ ${ }^{2}$ Department of Obstetrics and Gynaecology, Government Medical College and Hospital, Chandigarh 160030, India
}

Correspondence should be addressed to Rakesh Sehgal, sehgalpgi@gmail.com

Received 22 March 2012; Revised 5 July 2012; Accepted 18 August 2012

Academic Editor: Bryan Larsen

Copyright ( 2012 Rakesh Sehgal et al. This is an open access article distributed under the Creative Commons Attribution License, which permits unrestricted use, distribution, and reproduction in any medium, provided the original work is properly cited.

\begin{abstract}
Trichomonas vaginalis is a parasitic protozoan which infects the urogenital tract and requires iron as an essential nutrient. Iron is known to upregulate various adhesins required for cytoadherance and other factors involved in pathogenesis. At mucosal surfaces, iron is chelated by lactoferrin resulting in low levels of free iron. However, pathogens have evolved mechanisms for an increased uptake of iron. The present review highlights the role of iron in survival of Trichomonas during fluctuating concentrations of iron at mucosal surfaces during the menstrual cycle. Future prospects in terms of new drug and vaccine targets related to iron and its receptors have also been described.
\end{abstract}

\section{Introduction}

Trichomonas vaginalis is a flagellated, parasitic protozoan which causes trichomoniasis by infecting urogenital tract. Trichomoniasis is one of the most common causes of nonviral genitourinary sexually transmitted infection (STI) in humans with a worldwide prevalence of 170 million cases annually. According to WHO estimates, it accounts for almost half of all curable STIs [1]. Despite high prevalence, it is one of the poorly studied parasites with respect to virulence properties, pathogenesis, and immunopathogenesis. The present paper highlights the importance of various targets in pathogenesis where iron and its related transporting proteins play an important role. The role of lactoferrin (Lf) has been studied in various infections including parasitic infections, and in the present paper we will discuss the role of iron and lactoferrin in trichomoniasis.

\section{Brief Description of the Parasite}

T. vaginalis was discovered by Alfred Donné in 1836 and is an amitochondrial, microaerotolerant flagellate. Trichomonas vaginalis varies in shape and size. In a pure culture, typical shape of $T$. vaginalis is pyriform but amoeboid shapes have also been documented in parasites adhering to vaginal tissue. The average size of $T$. vaginalis is about 9 by $7 \mu \mathrm{m}$. It has five flagella; 4 are present anteriorly and the other flagellum is incorporated within the undulating membrane. It lacks a cystic stage and exists as a trophozoite. The trophozoite divides by binary fission and gives rise to progeny in the lumen or on the mucosal surfaces of urogenital tract of humans. Internal organelles include nucleus and axostyle which spans through the cell from anterior end to posterior end. Hydrogenosomes are the energy producing organelles, which appear as chromatic granules under light microscope [2].

\section{Transmission and Clinical Features}

Trophozoites of Trichomonas are transmitted from person to person through sexual contact. T. vaginalis trophozoites colonize the epithelial surface of the human urogenital tract in which they obtain nutrients, multiply, and face a constant challenge from host immune surveillance. The trophozoites divide by longitudinal binary fission after attaching themselves to mucosal surfaces of the urogenital tract. Incubation period varies from 4 to 28 days [3]. It can survive for long term in the acidic environment of vagina and the disease itself may be chronic. The clinical spectrum in women ranges from asymptomatic carrier state in approximately $50 \%$ of infected women, while symptomatic patients may suffer from mild-to-severe inflammation with a foul-smelling 
discharge and severe irritation. Infection during pregnancy may be associated with premature rupture of membranes, preterm delivery, and low-birth-weight babies. In men, the clinical spectrum varies from asymptomatic carrier state to acute state characterised by purulent urethritis, dysuria, or mild pruritus [4].

\section{Iron an Essential Nutrient}

Iron is an essential nutrient required for the survival of both humans and pathogenic protozoa. Iron is essential for wide range of biological process, including oxygen transport, DNA synthesis, and electron transport [5]. Some protozoa such as amitochondriate protists (e.g., Trichomonas, Giardia, and Entamoeba) require a high extracellular iron concentration $(50-200 \mu \mathrm{M})$ for their growth as compared to other prokaryotic or eukaryotic cells $(0.4-4 \mu \mathrm{M})$ [6]. Such a high concentration of iron is required for functional energy metabolism system which relies heavily on $\mathrm{Fe}-\mathrm{S}$ proteins [7]. To protect against invading pathogens mammals have evolved the scavenging mechanisms to limit the availability of iron near the vicinity of the pathogen. Ferric iron is chelated by lactoferrin which is an extracellular glycoprotein of the host immune system. Pathogens have also developed several mechanisms to obtain iron from the host hololactoferrin (holo-Lf) $[6,8]$. Thus, it is the delicate balance between the invading pathogen and host immune response which ultimately determine the clinical outcome.

\section{Iron as Ferric or Ferrous Ions}

Iron in the earth exists as ferric $\left(\mathrm{Fe}^{3+}\right)$ or ferrous $\left(\mathrm{Fe}^{2+}\right)$ state. It can accept or donate the electrons and catalyzes the important biochemical reactions such as the Fenton reaction: (a) $\mathrm{Fe}^{2+}+\mathrm{H}_{2} \mathrm{O}_{2} \rightarrow \mathrm{Fe}^{3+}+\mathrm{OH} \cdot+\mathrm{OH}^{-}$, (b) $\mathrm{Fe}^{3+}+\mathrm{H}_{2} \mathrm{O}_{2} \rightarrow$ $\mathrm{Fe}^{2+}+\mathrm{OOH} \cdot+\mathrm{H}^{+}$. It catalyses the conversion of hydrogen peroxide to toxic free radicals $[9,10]$. Thus, it cannot be available in the free state in tissues or cells: it is available only bound to proteins, limiting its ability to cause the damage. Intracellular iron is bound to ferritin or it is present within hemoglobin as a major iron content of the body. Extracellular iron is bound to transferrin which helps in transferring the iron to all cells and at mucosal surfaces it is bound to lactoferrin (Lf) $[6,8]$.

\section{Lactoferrin (Lf)}

Lactoferrin (Lf) is a mammalian non-heme iron-binding glycoprotein which can bind two ferric ions with very high affinity even at an acidic $\mathrm{pH}$ of $2.5-4$ [11, 12]. A glycan moiety provides the protection from proteolysis and also helps in decreasing its immunogenicity [13]. Lf exists in two different conformations which are governed by the iron binding status and these are apo-Lf (without iron) and holo-Lf (with iron) [14]. Apo-Lf has an open conformation which can bind to iron, and holo-Lf exhibits a closed conformation which is saturated with iron. Lf is a highly conserved glycoprotein having a homology of approximately $70 \%$ between humans and mice and greater than $70 \%$ between humans and cattle with respect to amino acid sequence [15].

Lf is found in various mucosal secretions, including saliva, tears, vaginal fluids, semen, nasal and bronchial secretions, gastrointestinal fluids, urine, and most abundantly in milk and colostrum $[16,17]$. It is also found in blood, amniotic fluid, and in secondary neutrophils granules, where it plays an important physiological role [18].

\section{Functions of Lactoferrin (Lf)}

Lf is a multifunctional protein with a wide range of biological activities including regulation of iron absorption, immune response, antioxidant, anticarcinogenic, anti-inflammatory properties, and antimicrobial activity [12, 19-21]. Recently, Lf is emerged as a pivotal component of iron and inflammatory homeostasis capable of overcoming pregnancyassociated anemia, while decreasing serum IL-6 levels [2224].

\section{Anti-Inflammatory Properties of Lf}

In vivo and in vitro evidence characterizes Lf as a potent antiinflammatory compound able to reverse/attenuate inflammatory response triggered by Toll-like receptor (TLR) engagement in antigen-presenting cells. Recently, Puddu et al. [25] have shown that monocyte-derived dendritic cells (MD-DCs) generated in the presence of bovine Lf (bLf) failed to undergo activation by upmodulating CD83, costimulatory and major histocompatibility complex molecules. Consistent with an impaired maturation, bLf-MD-DC primed $\mathrm{T}$ lymphocytes exhibit a unresponsiveness characterized by impaired expression of IFN- $\gamma$ and IL-2. These immunosuppressive effects correlate with an increased expression of molecules with negative regulatory functions. Berlutti et al. [26] have shown that Lf downregulates proinflammatory cytokines in intestinal epithelial cells infected with invasive and noninvasive Escherichia coli strains. Valenti et al. [27] have also shown similar anti-inflammatory activity of Lf in cystic fibrosis bronchial cells invaded by Burkholderia cenocepacia. Thus, Lf may be used as a therapeutic agent as it prevents the inflammation-related damage. Little information is available about the molecular details of interaction of Lf with the cells to mediate its effects. Recently, a study by Suzuki et al. [28] has shown that the N1 domain of human Lf is required for internalization by caco- 2 cells and targeting to the nucleus to mediate its effects.

\section{Microbiostatic and Microbicidal Effects}

Apo-Lf is secreted as microbicidal product by secondary granules of neutrophils. Thus, apo-Lf sequesters the iron at the site of infection, resulting in deprivation of iron to microbes. Hence, microbes must compete with host Lf to meet their iron requirement. Due to its iron-chelating property, it is known as microbiostatic [29]. Apo-Lf is a highly cationic in nature and thus, readily binds to anionic 
charges on bacterial surfaces, provided by lipopolysaccharides, porins, and teichoic acids. Such binding results in destabilizing the bacterial membrane [30]. Apo-Lf also exhibits a synergistic effect with IgA, lysozyme, antibiotics, and drugs which helps in eradication of microorganisms $[20,31]$.

\section{Lactoferrin Friend or Foe}

When apo-Lf acquires iron, it becomes saturated with iron and forms holo-Lf which is an important source of iron for microbes. Thus, iron not only abolishes Lf's innate immune effect but also acts a source of nutrition to microbes. Microbes have developed the various strategies to acquire the iron from holo-Lf which helps them in replication causing acute or chronic infections and damage to host. Thus, for microbes iron-loaded Lf is a friend but becomes a foe when iron is not present $[29,32]$.

\section{Mechanisms Adopted by Parasites to Acquire Iron from Holo-Lf}

Basically there are four different mechanisms by which parasites acquire iron as a source of nutrient from holo-Lf and these are as follows [33].

(1) Lf Binding Receptor. Expression of lactoferrin binding receptors or proteins (Lbps) which directly bind to holo-Lf (Trichomonas vaginalis).

(2) Enzymatic Degradation. Secretion of proteases to cleave holo-Lf to release iron as a source of nutrient (Tritrichomonas fetus and Entamoeba histolytica).

(3) Reducing Enzymes. Reductases help in reducing the ferric state to ferrous state which is more useful to the parasite (Leishmania spp.).

(4) Xenosiderophores. This mechanism is used by bacteria and fungi to obtain iron by producing and secreting siderophores, which have high affinity for iron. They can remove iron from holo-Lf, which in turn is captured by specific receptors, and after providing iron to the pathogen, siderophore again becomes available to carry fresh iron from the environment [34]. Tritrichomonas fetus is able to use a wide range of foreign siderophores in vitro (ferrioxamine $\mathrm{B}$, coprogen, ferrichrome, enterobactin, and pyoverdine) [35].

\section{Iron Acquisition by Trichomonas Is Receptor Mediated}

T. vaginalis acquire iron either from holo-Lf or hemoglobin $[36,37]$. It recognizes human holo-Lf by two surface proteins which are 178 and $75 \mathrm{kDa}$. Approximately 90,000 receptors have been documented to be present on each trichomonad. T. vaginalis only recognizes holo- $\mathrm{Lf}$, as it is not able to recognize apo-LF or holotransferrin (holo-Tf). A study by Lehker and Alderete [38] has shown the dynamics of lactoferrin-binding proteins and receptors to changing iron concentration. Lf-binding activity has been shown to be increased by 1.6-fold, under iron-depleted conditions as compared to iron rich conditions. Increase in Lf-binding activity has also been documented when trichomonads with depleted intracellular iron pools were assayed. It has also been observed that a number of holo-Lf-binding receptors increase 2.5 times when trichomonads were cultivated in iron-depleted conditions compared to iron rich-conditions. The number and affinity of holo-Lf receptors in response to changing external and internal iron concentrations clearly shows relevance to in vivo situations. Lf concentration in human vaginal mucosa constantly fluctuates throughout the menstrual cycle, varying from $9 \mu \mathrm{g} / \mathrm{mL}$ during mid cycle to $200 \mu \mathrm{g} / \mathrm{mL}$ [39]. Thus, increased affinity during decreased Lf concentration may be a successful mechanism to obtain iron during such conditions.

\section{Role of Iron on Growth of $T$. vaginalis In Vitro}

Yuan and Xue [40] have shown the effect of varying concentration of iron in the TYM (trypticase-yeast extractmaltose) medium for trophozoites of $T$. vaginalis. The generation times were found to be shorter when trophozoites were grown in iron-rich conditions $(100-400 \mu \mathrm{mol} / \mathrm{L}$ iron ion). Minimal lethal concentration (MLC) of metronidazole, tested by serial dilution method, was found to be significantly lower in iron-rich media as compared to control group.

\section{Role of Iron in Cytoadherence}

Levels of cytoadherence to HeLa cells have been found to be modulated by different iron levels. Trichomonads isolated from iron-rich media have been shown to mediate higher level of cytoadherence. The extent and expression of adherence property is directly proportional to the concentration of iron added to the medium. This increase in cytoadherence is mediated by increase in expression of genes coding for adhesins. Under iron-rich conditions, increased synthesis of adhesins mediate better cytoadherence. Actinomycin D and alpha-amanitin have been shown to prevent the expression of adhesin molecules resulting in decreased cytoadherence. Thus, iron upregulates the expression of adhesins and the level of cytoadherence, representing an important initial step in pathogenesis. The mucus layer of the vaginal tract is the first barrier encountered by the T. vaginalis. Trichomonas interacts specifically with the mucin, the predominant component of the mucus. Then the organism comes in contact with the vaginal epithelium cells (VECs) which are under the influence of various hormonal changes induced by the menstrual cycle. So, to colonize the vaginal epithelium $T$. vaginalis has evolved multiple mechanisms. Lipophosphoglycan (LPG) is a major adherence factor but other proteins which help in cytoadherence are adhesion proteins (AP), fibronectin (FN)-binding protein, lamininbinding protein, $\alpha$-actinin, enolase, phosphoglucomutase, 
GTP-binding protein (GTP-BP) [41-43]. There occurs an upregulation of four major iron-regulated adhesion proteins (AP65, AP51, AP33, and AP23), GAPDH, and several hypothetical proteins in a specific receptor-ligand fashion. These APs have sequence homology to metabolic enzymes and the majority are positively regulated by iron at the level of transcription and translation. The ap65-1 gene encodes a $65 \mathrm{kDa}$ malic enzyme involved in cytoadherence [43]. The transcription of this gene is critically regulated by its promoter region where presence of multiple closely spaced DNA regulatory elements regulate iron-induced transcription [44].

Another $120 \mathrm{kDa}$ adhesion protein (AP120) is also induced under iron-rich conditions and has sequence homology with pyruvate: ferredoxin oxidoreductase A (PFO A), a hydrogenosomal enzyme that is absent in humans $[7,45]$. The main function of the hydrogenosome, an organelle typical of trichomonads, and converting malate or pyruvate to $\mathrm{H}_{2}, \mathrm{CO}_{2}$, and acetate by a pathway associated with ATP synthesis. This pathway relies on activity of iron-sulphur proteins such as pyruvate: ferredoxin oxidoreductase (PFOR), hydrogenase, and ferredoxin. Studies have shown that like AP120, PFO is localized to the parasite surface and participates in cytoadherence [46]. Thus, T. vaginalis PFO is an example of a surfaceassociated cell-binding protein which lacks enzyme activity and is involved in cytoadherence. Additionally, PFO behaves like AP120 in parasites, when grown under iron-rich conditions.

These adhesion proteins help parasite attachment and their role in pathogenesis has been confirmed by coculture experiments. It has been shown in these experiments that antibodies to adhesion proteins (APs) reduce the parasite adhesion and subsequent cytopathic effects (CE) on host cells. FN-binding proteins bind to multiple FN domains including the cell-binding domain (CBD), N-terminal domain (NTD), and gelatine-binding domain (GBD). During these processes, iron along with calcium and phosphatase is essentially required for differential gene expression which helps in survival, growth, and colonization of parasite in the vaginal hostile environment $[42,47]$.

T. vaginalis glutaraldehyde-3-phosphate dehydrogenase (GAPDH) has been identified as a fibronectin-binding protein that is localized at the parasite surface. The expression and surface localization of GAPDH are positively regulated by iron $[41,48]$. Thus, $T$. vaginalis is part of a growing list of microbial pathogens that contain surface-associated enzymes that have alternate, nonenzymic functions. However, the mechanisms by which these enzymes are localized at the Trichomonas surface and the pathways in which they act are poorly understood.

The responses of $T$. vaginalis to iron limitation or iron excess have been well established. There is $\sim 80 \%$ lower rates of protein synthesis and $\geq 3$-fold decrease in cell densities when organisms are grown in iron-limited culture system as compared to iron-rich conditions. These parasites also exhibit generation times of approximately 10 hours, 2.5 -fold longer than organisms grown in the usual complex medium [49].

\section{Effect of Iron on the Virulence of $T$. vaginalis}

Iron is an essential element which has a significant effect on the virulence of $T$. vaginalis. Ryu et al. [50] evaluated the role of iron in relation to the virulence of $T$. vaginalis in mice. Trophozoites cultivated from normal Diamond's trypticaseyeast extract-maltose (TYM) media and iron-supplemented TYM media produced subcutaneous abscesses, whereas trophozoites cultivated in iron-deficient media failed to produce any pathology. Iron also affects the level of adherence and the cytotoxicity of trichomonads to HeLa cells, which are significantly reduced when trophozoites were cultivated in iron-deficient media.

\section{Iron Upregulates Proteinases Involved in Complement Resistance}

It has been seen that $T$. vaginalis is readily lysed by the activation of alternative complement pathway. However, parasites become resistant to complement when grown in ironrich media. The resistance to complement has been shown to be dependent on iron concentration, and other divalent ions other than iron do not modulate the complement activity. Lactoferrin is known to provide the iron source to the trophozoites and it also renders the low-iron parasites resistant to complement lysis. Pretreatment of high-iron, complement-resistant parasites with proteinase inhibitors prevented the degradation of $\mathrm{C} 3$ on the trichomonal surface and results in degradation of parasite by complement activity. Thus, proteinases are the enzymes which provide resistance to complement degradation when iron sources are available [51].

T. vaginalis faces the profound change in the environment during menstrual cycle. The vaginal microenvironment undergoes dramatic change during menstruation as it is flooded with serum proteins, erythrocytes, and other macromolecules. During this stage, T. vaginalis encounters the complement which is an important effector system against $T$. vaginalis infection. Activation of alternative complement system does not require antibodies and it can be activated by magnesium ions, factors $\mathrm{B}$ and $\mathrm{D}$, properdin, and $\mathrm{C} 3$ for activation. It has been observed that menstrual blood complement is trichomonacidal, mediated by activation of alternative pathway. However, trichomonads are known to undergo adaptive changes in vivo, which enable the parasites to avoid lysis by complement as a survival strategy [51]. Most important being the iron which regulates the gene expression of surface immunogens and adhesions as described above.

Even after menstruation, infection persists as some parasites evade the immune mechanism of alternative complement pathway by secreting various proteinases. These proteinases not only help the parasites acquire the nutrients through lysis of erythrocytes but also help in recognition and binding to host cells. Thus, trichomonad proteinases have dual role in host pathology and parasite survival. 


\section{Iron Modulates Major Surface Immunogen P270}

P270 is an immunogenic protein which causes phenotypic variation of $T$. vaginalis infected with double-stranded RNA virus (designated as TVV: T. vaginalis virus) $[52,53]$ on the basis of its differential cytoplasmic versus surface expression. Two types of isolates have been documented during infection with $T$. vaginalis. Type I isolates comprise homogeneous nonfluorescent (negative phenotype) trichomonads which synthesize and express P270 in the cytoplasm. In contrast, type II isolates comprise both fluorescent and nonfluorescent subpopulations (positive and negative phenotypes). Growth of virus-positive organisms in high-iron medium induces expression of trichomonad adhesins but yields parasites without surface P270. P270 has been found to be highly phosphorylated in high-iron parasites and modulating the low surface expression of P270. Thus, iron plays a role in modulating surface localization of P270 in virus-harbouring parasites [54].

\section{Irony about Iron Regulation of CP65 Cysteine Proteinase}

It has been seen that iron is essential for the virulence of the parasite and Trichomonas has evolved different strategies for acquiring iron. In T. vaginalis, iron up-regulates amounts of adhesins and levels of cytoadherence [55, 56]. Iron also up-regulates the cysteine proteinases (CPs) involved in complement resistance and several parasite functions as described above. However, a study by Alvarez-Sánchez et al. [57] has shown that iron specifically down-regulates proteolytic activity, expression, and transcription of CP65, negatively affecting trichomonal cytotoxicity in vitro. Several CPs participate in the virulence of Trichomonas vaginalis and $65 \mathrm{kDa} \mathrm{CP}, \mathrm{CP} 65$, is one involved in cytotoxicity. A similar effect has also been observed with CP39, involved in cytotoxicity [58]. Similarly, iron also downregulates the other genes such as tvcp12 and flp-1,2 which encodes for papainlike CP and fibronectin-like proteins, respectively $[59,60]$. Thus, it is very surprising that similar iron concentrations exert opposite effects on expression of adhesions and some CPs. This irony has been explained by the fact that iron concentration fluctuates in the vagina during menstrual cycle. Lactoferrin concentration is also known to vary during the different phases of menstrual cycle; that is, it is present in highest concentration after the menstruation and decreases progressively during the cycle with minimum levels present immediately before menstruation. Trichomonas has evolved the two different mechanisms to maintain its pathogenicity at different phases of menstrual cycle which helps in its survival. It has been postulated that just before the menstruation when iron concentration is lowest, $T$. vaginalis may enhance the level of cytotoxicity by increasing the CP65 activity. Simultaneously, low iron levels may reduce the expression of adhesions leading to decreased level of cytoadherence, allowing the parasite to move around in search for new iron sources. The opposite effect might be occurring during the highest level of iron concentrations (during and after menstruation); there occurs an up-regulation of adhesin expression, providing an opportunity for the parasites to adhere firmly to prevent the flushing by menstrual blood flow [57].

\section{Future Prospects}

Drug resistance among the protozoa is increasing at an alarming rate, with relatively few options left for the treatment. In 1962, resistance among T. vaginalis was first reported [61] and is at risk of developing increased resistance to recommended therapeutics due to empirical use of drugs. The 5-nitroimidazole family of drugs (metronidazole and tinidazole) are the only class of drugs approved for the treatment of trichomoniasis [62] and P. Upcroft and J. A. Upcroft [63] have reported up to $10 \%$ of infections which are not responding to treatment in the United States. Resistant organisms are cosmopolitan in distribution and are of considerable concern as Trichomonas infections are linked to human immunodeficiency virus (HIV) transmission. Further scientific research is required to fill the gaps in knowledge about understanding the pathogenesis, so that newer drug targets can be evaluated in order to overcome the increasing burden of drug resistance.

\section{T. vaginalis Receptor as a Vaccine Candidate}

Lehker and Alderete [38] examined the sera of patients by immunoblotting to detect the proteins from parasites grown in low- and high-iron media, recognized by antibodies. Twelve trichomonad immunogens from parasites grown in iron-rich medium and 7 from those grown in lowiron medium were found. Sera from patients with vaginitis recognized the purified Lf receptor protein. Thus, T. vaginalis receptor could be tested as a vaccine candidate.

\section{Drug Delivery}

Lf may be used as a carrier for drug delivery as it specifically binds to receptor at the surface of Trichomonas. Moreover, it is concentrated at places where infection is present at the mucosal surface.

\section{Inhibition of Lf and Receptor Binding}

Inhibition of Lf binding sites at Trichomonas surface may deprive the parasites from iron availability and can be used as an attractive therapeutic strategy.

Thus, search for newer drug targets and vaccine candidates in relation to lactoferrin, its receptors, and Trichomonas is required in coming years to win the fight against this parasite.

\section{Conclusion}

Iron is an essential nutrient required by $T$. vaginalis to maintain its virulence in changing vaginal environment due to 
cyclic menstruation. Trichomonas has evolved the receptormediated uptake of iron through holo-Lf and its concentration and affinity vary according to the availability of iron in the external environment. Usually, iron is known to upregulate various adhesins and other factors which increase which help in maintaining the virulence. However, it has been seen that cystein proteinases (CP65 and CP39) are downregulated when the external iron concentration is high. It is important for the survival of parasite as when abundant iron is available, that is, during menstrual flow, there is an increase in cytoadherence, preventing flushing of parasites during blood flow of menstruation. On the other hand, just before menstruation, iron concentration is low; thus cytoadhesion is also decreased and CP65 and CP39 are activated which help moving the parasite in search of iron and maintain its virulence. Furthermore, drugs can be formulated which can target the holo-Lf receptor or various immunogens can be tested which can provide immunity or holo-Lf can be used a carrier for drug delivery. However, studies are required in animal models to check the efficacy and adverse effects of new drugs, targeting Lf or its receptor. At present there is no drug available which targets the Lf or its receptor for the treatment of trichomoniasis. Finally to conclude apo-Lf is lethal to parasite, but when it acquires iron (holo-Lf), it is used as a iron source by the parasite.

\section{References}

[1] R. S. McClelland, "Trichomonas vaginalis infection: can we afford to do nothing?" Journal of Infectious Diseases, vol. 197, no. 4, pp. 487-489, 2008.

[2] D. Petrin, K. Delgaty, R. Bhatt, and G. Garber, "Clinical and microbiological aspects of Trichomonas vaginalis," Clinical Microbiology Reviews, vol. 11, no. 2, pp. 300-317, 1998.

[3] J. R. Schwebke and D. Burgess, "Trichomoniasis," Clinical Microbiology Reviews, vol. 17, no. 4, pp. 794-803, 2004.

[4] P. Heine and J. A. McGregor, "Trichomonas vaginalis: a reemerging pathogen," Clinical Obstetrics and Gynecology, vol. 36, no. 1, pp. 137-144, 1993.

[5] T. Goswami, A. Rolfs, and M. A. Hediger, "Iron transport: emerging roles in health and disease," Biochemistry and Cell Biology, vol. 80, no. 5, pp. 679-689, 2002.

[6] E. D. Weinberg, "Iron and susceptibility to infectious disease," Science, vol. 184, no. 4140, pp. 952-956, 1974.

[7] S. Vanacova, D. Rasoloson, J. Rázga, I. Hrdý, J. Kulda, and J. Tachezy, "Iron-induced changes in pyruvate metabolism of Tritrichomonas foetus and involvement of iron in expression of hydrogenosomal proteins," Microbiology, vol. 147, no. 1, pp. 53-62, 2001.

[8] U. E. Schaible and S. H. E. Kaufmann, "Iron and microbial infection,” Nature Reviews Microbiology, vol. 2, no. 12, pp. 946-953, 2004.

[9] L. L. Dunn, Y. S. Rahmanto, and D. R. Richardson, "Iron uptake and metabolism in the new millennium," Trends in Cell Biology, vol. 17, no. 2, pp. 93-100, 2007.

[10] A. S. Zhang and C. A. Enns, "Iron homeostasis: recently identified proteins provide insight into novel control mechanisms," Journal of Biological Chemistry, vol. 284, no. 2, pp. 711-715, 2009.

[11] E. N. Baker and H. M. Baker, "Molecular structure, binding properties and dynamics of lactoferrin," Cellular and Molecular Life Sciences, vol. 62, no. 22, pp. 2531-2539, 2005.
[12] D. Legrand, A. Pierce, E. Elass, M. Carpentier, C. Mariller, and J. Mazurier, "Lactoferrin structure and functions," Advances in Experimental Medicine and Biology, vol. 606, pp. 163-194, 2008.

[13] H. A. Van Veen, M. E. J. Geerts, P. H. C. Van Berkel, and J. H. Nuijens, "The role of N-linked glycosylation in the protection of human and bovine lactoferrin against tryptic proteolysis," European Journal of Biochemistry, vol. 271, no. 4, pp. 678-684, 2004.

[14] L. H. Vorland, "Lactoferrin: a multifunctional glycoprotein," APMIS, vol. 107, no. 11, pp. 971-981, 1999.

[15] L. A. Lambert, "Molecular evolution of the transferrin family and associated receptors," Biochimica et Biophysica Acta, vol. 1820, no. 3, pp. 244-255, 2012.

[16] B. W. A. Van der Strate, L. Beljaars, G. Molema, M. C. Harmsen, and D. K. F. Meijer, "Antiviral activities of lactoferrin," Antiviral Research, vol. 52, no. 3, pp. 225-239, 2001.

[17] P. P. Ward, E. Paz, and O. M. Conneely, "Multifunctional roles of lactoferrin: a critical overview," Cellular and Molecular Life Sciences, vol. 62, no. 22, pp. 2540-2548, 2005.

[18] R. M. Bennett and T. Kokocinski, "Lactoferrin content of peripheral blood cells," British Journal of Haematology, vol. 39, no. 4, pp. 509-521, 1978.

[19] D. Legrand, E. Elass, M. Carpentier, and J. Mazurier, "Lactoferrin: a modulator of immune and inflammatory responses," Cellular and Molecular Life Sciences, vol. 62, no. 22, pp. 25492559, 2005.

[20] P. Valenti and G. Antonini, "Lactoferrin: an important host defence against microbial and viral attack," Cellular and Molecular Life Sciences, vol. 62, no. 22, pp. 2576-2587, 2005.

[21] P. Puddu, P. Valenti, and S. Gessani, "Immunomodulatory effects of lactoferrin on antigen presenting cells," Biochimie, vol. 91, no. 1, pp. 11-18, 2009.

[22] R. Paesano, F. Torcia, F. Berlutti et al., "Oral administration of lactoferrin increases hemoglobin and total serum iron in pregnant women," Biochemistry and Cell Biology, vol. 84, no. 3, pp. 377-380, 2006.

[23] R. Paesano, F. Berlutti, M. Pietropaoli et al., "Lactoferrin efficacy versus ferrous sulfate in curing iron deficiency and iron deficiency anemia in pregnant women," BioMetals, vol. 23, no. 3, pp. 411-417, 2010.

[24] R. Paesano, M. Pietropaoli, S. Gessani, and P. Valenti, "The influence of lactoferrin, orally administered, on systemic iron homeostasis in pregnant women suffering of iron deficiency and iron deficiency anaemia," Biochimie, vol. 91, no. 1, pp. 4451, 2009.

[25] P. Puddu, D. Latorre, M. Carollo et al., "Bovine lactoferrin counteracts Toll-like receptor mediated activation signals in antigen presenting cells," PLoS One, vol. 6, no. 7, Article ID e22504, 2011.

[26] F. Berlutti, S. Schippa, C. Morea et al., "Lactoferrin downregulates pro-inflammatory cytokines upexpressed in intestinal epithelial cells infected with invasive or noninvasive Escherichia coli strains," Biochemistry and Cell Biology, vol. 84, no. 3, pp. 351-357, 2006.

[27] P. Valenti, A. Catizone, F. Pantanella et al., "Lactoferrin decreases inflammatory response by cystic fibrosis bronchial cells invaded with Burkholderia cenocepacia iron-modulated biofilm," International Journal of Immunopathology and Pharmacology, vol. 24, no. 4, pp. 1057-1068, 2011.

[28] Y. A. Suzuki, H. Wong, K. Y. Ashida, A. B. Schryvers, and B. Lönnerdal, "The N1 domain of human lactoferrin is required for internalization by caco- 2 cells and targeting to the nucleus," Biochemistry, vol. 47, no. 41, pp. 10915-10920, 2008. 
[29] J. J. Bullen, "The significance of iron in infection," Reviews of Infectious Diseases, vol. 3, no. 6, pp. 1127-1138, 1981.

[30] E. Elass, M. Masson, J. Mazurier, and D. Legrand, "Lactoferrin inhibits the lipopolysaccharide-induced expression and proteoglycan-binding ability of interleukin-8 in human endothelial cells," Infection and Immunity, vol. 70, no. 4, pp. 1860-1866, 2002.

[31] N. León-Sicairos, F. López-Soto, M. Reyes-López, D. GodínezVargas, C. Ordaz-Pichardo, and M. De La Garza, "Amoebicidal activity of milk, apo-lactoferrin, slgA and lysozyme," Clinical Medicine and Research, vol. 4, no. 2, pp. 106-113, 2006.

[32] E. D. Weinberg, "Iron availability and infection," Biochimica et Biophysica Acta, vol. 1790, no. 7, pp. 600-605, 2009.

[33] G. Ortíz-Estrada, S. Luna-Castro, C. Piña-Vázquez et al., "Iron-saturated lactoferrin and pathogenic protozoa: could this protein be an iron source for their parasitic style of life?" Future Microbiology, vol. 7, no. 1, pp. 149-164, 2012.

[34] E. D. Weinberg, "Microbial pathogens with impaired ability to acquire host iron," BioMetals, vol. 13, no. 1, pp. 85-89, 2000.

[35] R. Sutak, C. Chamot, J. Tachezy, J. M. Camadro, and E. Lesuisse, "Siderophore and haem iron use by Tritrichomonas foetus," Microbiology, vol. 150, no. 12, pp. 3979-3987, 2004.

[36] K. M. Peterson and J. F. Alderete, "Iron uptake and increased intracellular enzyme activity follow host lactoferrin binding by Trichomonas vaginalis receptors," Journal of Experimental Medicine, vol. 160, no. 2, pp. 398-410, 1984.

[37] M. W. Lehker, T. H. Chang, D. C. Dailey, and J. F. Alderete, "Specific erythrocyte binding is an additional nutrient acquisition system for Trichomonas vaginalis," Journal of Experimental Medicine, vol. 171, no. 6, pp. 2165-2170, 1990.

[38] M. W. Lehker and J. F. Alderete, "Iron regulates growth of Trichomonas vaginalis and the expression of immunogenic trichomonad proteins," Molecular Microbiology, vol. 6, no. 1, pp. 123-132, 1992.

[39] M. S. Cohen, B. E. Britigan, M. French, and K. Bean, "Preliminary observations on lactoferrin secretion in human vaginal mucus: variation during the menstrual cycle, evidence of hormonal regulation, and implications for infection with Neisseria gonorrhoeae," American Journal of Obstetrics and Gynecology, vol. 157, no. 5, pp. 1122-1125, 1987.

[40] Y. Q. Yuan and C. G. Xue, "Influence of iron ion on the growth of Trichomonas vaginalis in vitro," Chinese Journal of Parasitology \& Parasitic Diseases, vol. 28, no. 4, pp. 273-276, 2010.

[41] J. F. Alderete, M. Benchimol, M. W. Lehker, and M. L. Crouch, "The complex fibronectin-Trichomonas vaginalis interactions and Trichomonosis," Parasitology International, vol. 51, no. 3, pp. 285-292, 2002.

[42] M. L. Crouch, M. Benchimol, and J. F. Alderete, "Binding of fibronectin by Trichomonas vaginalis is influenced by iron and calcium," Microbial Pathogenesis, vol. 31, no. 3, pp. 131-144, 2001.

[43] A. S. Kucknoor, V. Mundodi, and J. F. Alderete, "The proteins secreted by Trichomonas vaginalis and vaginal epithelial cell response to secreted and episomally expressed AP65," Cellular Microbiology, vol. 9, no. 11, pp. 2586-2597, 2007.

[44] H. M. Hsu, S. J. Ong, M. C. Lee, and J. H. Tai, “Transcriptional regulation of an iron-inducible gene by differential and alternate promoter entries of multiple Myb proteins in the protozoan parasite Trichomonas vaginalis," Eukaryotic Cell, vol. 8, no. 3, pp. 362-372, 2009.

[45] T. E. Gorrell, "Effect of culture medium iron content on the biochemical composition and metabolism of Trichomonas vaginalis," Journal of Bacteriology, vol. 161, no. 3, pp. 12281230, 1985.

[46] V. Moreno-Brito, C. Yanez-Gomez, P. Meza-Cervantez et al., "A Trichomonas vaginalis $120 \mathrm{kDa}$ protein with identity to hydrogenosome pyruvate:ferredoxin oxidoreductase is a surface adhesin induced by iron," Cellular Microbiology, vol. 7, no. 2, pp. 245-258, 2005.

[47] D. F. Harp and I. Chowdhury, "Trichomoniasis: evaluation to execution," European Journal of Obstetrics Gynecology and Reproductive Biology, vol. 157, no. 1, pp. 3-9, 2011.

[48] A. Lama, A. Kucknoor, V. Mundodi, and J. F. Alderete, "Glyceraldehyde-3-phosphate dehydrogenase is a surface-associated, fibronectin-binding protein of Trichomonas vaginalis," Infection and Immunity, vol. 77, no. 7, pp. 2703-2711, 2009.

[49] C. D. Tsai, H. W. Liu, and J. H. Tai, "Characterization of an iron-responsive promoter in the protozoan pathogen Trichomonas vaginalis," Journal of Biological Chemistry, vol. 277, no. 7, pp. 5153-5162, 2002.

[50] J. S. Ryu, H. K. Choi, D. Y. Min, S. E. Ha, and M. H. Ahn, "Effect of iron on the virulence of Trichomonas vaginalis," Journal of Parasitology, vol. 87, no. 2, pp. 457-460, 2001.

[51] J. F. Alderete, D. Provenzano, and M. W. Lehker, "Iron mediates Trichomonas vaginalis resistance to complement lysis," Microbial Pathogenesis, vol. 19, no. 2, pp. 93-103, 1995.

[52] A. L. Wang and C. C. Wang, "The double-stranded RNA in Trichomonas vaginalis may originate from virus-like particles," Proceedings of the National Academy of Sciences of the United States of America, vol. 83, no. 20, pp. 7956-7960, 1986.

[53] A. Wang, C. C. Wang, and J. F. Alderete, "Trichomonas vaginalis phenotypic variation occurs only among trichomonads infected with the double-stranded RNA virus," Journal of Experimental Medicine, vol. 166, no. 1, pp. 142-150, 1987.

[54] J. F. Alderete, "Iron modulates phenotypic variation and phosphorylation of P270 in double-stranded RNA virusinfected Trichomonas vaginalis," Infection and Immunity, vol. 67, no. 8, pp. 4298-4302, 1999.

[55] M. W. Lehker, R. Arroyo, and J. F. Alderete, "The regulation by iron of the synthesis of adhesins and cytoadherence levels in the protozoan Trichomonas vaginalis," Journal of Experimental Medicine, vol. 174, no. 2, pp. 311-318, 1991.

[56] A. F. Garcia, T. H. Chang, M. Benchimol, D. J. Klumpp, M. W. Lehker, and J. F. Alderete, "Iron and contact with host cells induce expression of adhesins on surface of Trichomonas vaginalis," Molecular Microbiology, vol. 47, no. 5, pp. 12071224, 2003.

[57] M. E. Alvarez-Sánchez, E. Solano-González, C. Yañez-Gómez, and R. Arroyo, "Negative iron regulation of the CP65 cysteine proteinase cytotoxicity in Trichomonas vaginalis," Microbes and Infection, vol. 9, no. 14-15, pp. 1597-1605, 2007.

[58] R. Hernandez-Gutierrez, J. Ortega-López, and R. Arroyo, “A $39-\mathrm{kDa}$ cysteine proteinase CP39 from Trichomonas vaginalis, which is negatively affected by iron may be involved in Trichomonal Cytotoxicity," Journal of Eukaryotic Microbiology, vol. 50, pp. 696-698, 2003.

[59] C. R. León-Sicairos, J. León-Félix, and R. Arroyo, “Tvcp12: a novel Trichomonas vaginalis cathepsin L-like cysteine proteinase-encoding gene," Microbiology, vol. 150, no. 5, pp. 1131-1138, 2004.

[60] M. L. V. Crouch and J. F. Alderete, "Trichomonas vaginalis has two fibronectin-like iron-regulated genes," Archives of Medical Research, vol. 32, no. 2, pp. 102-107, 2001.

[61] S. C. Robinson, "Trichomonal Vaginitis Resistant to Metranidazole," Canadian Medical Association Journal, vol. 86, p. 665, 1962. 
[62] R. L. Dunne, L. A. Dunn, P. Upcroft, P. J. O’Donoghue, and J. A. Upcroft, "Drug resistance in the sexually transmitted protozoan Trichomonas vaginalis," Cell Research, vol. 13, no. 4, pp. 239-249, 2003.

[63] P. Upcroft and J. A. Upcroft, "Drug targets and mechanisms of resistance in the anaerobic protozoa," Clinical Microbiology Reviews, vol. 14, no. 1, pp. 150-164, 2001. 


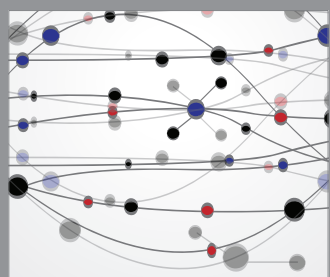

The Scientific World Journal
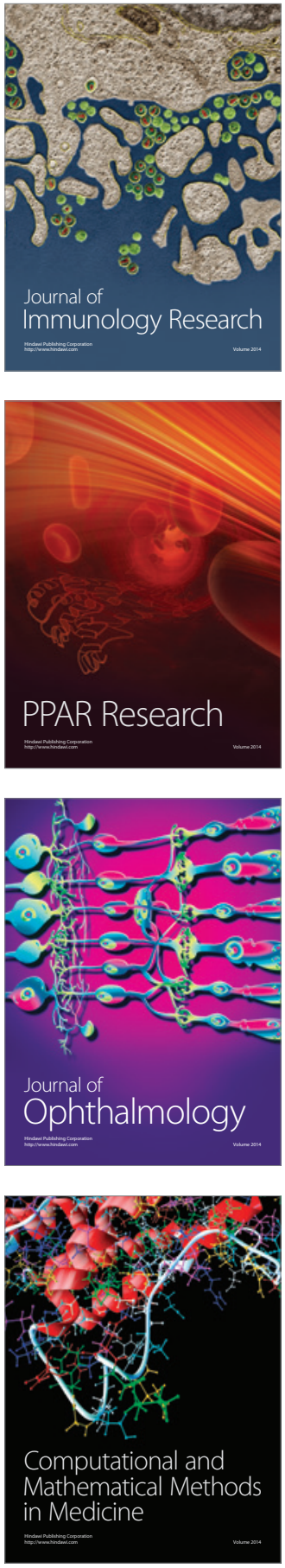

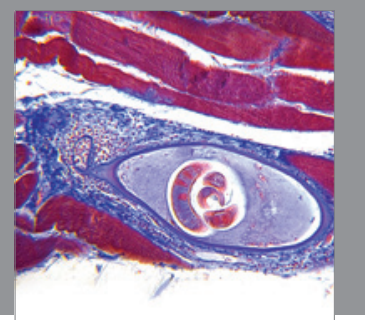

Gastroenterology

Research and Practice
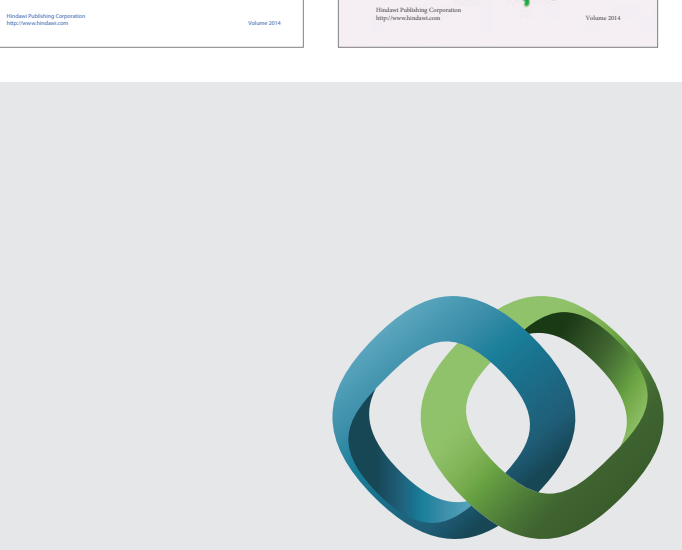

\section{Hindawi}

Submit your manuscripts at

http://www.hindawi.com
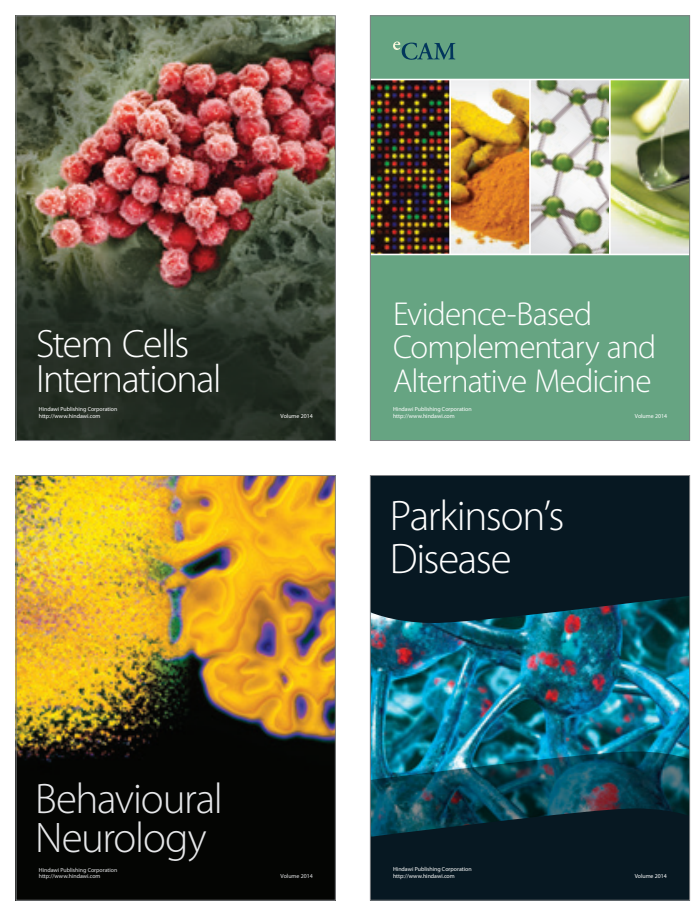

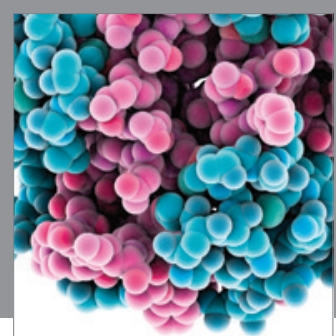

Journal of
Diabetes Research

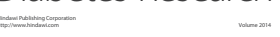

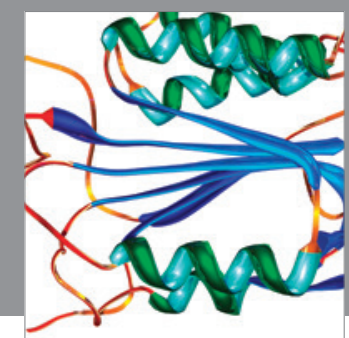

Disease Markers
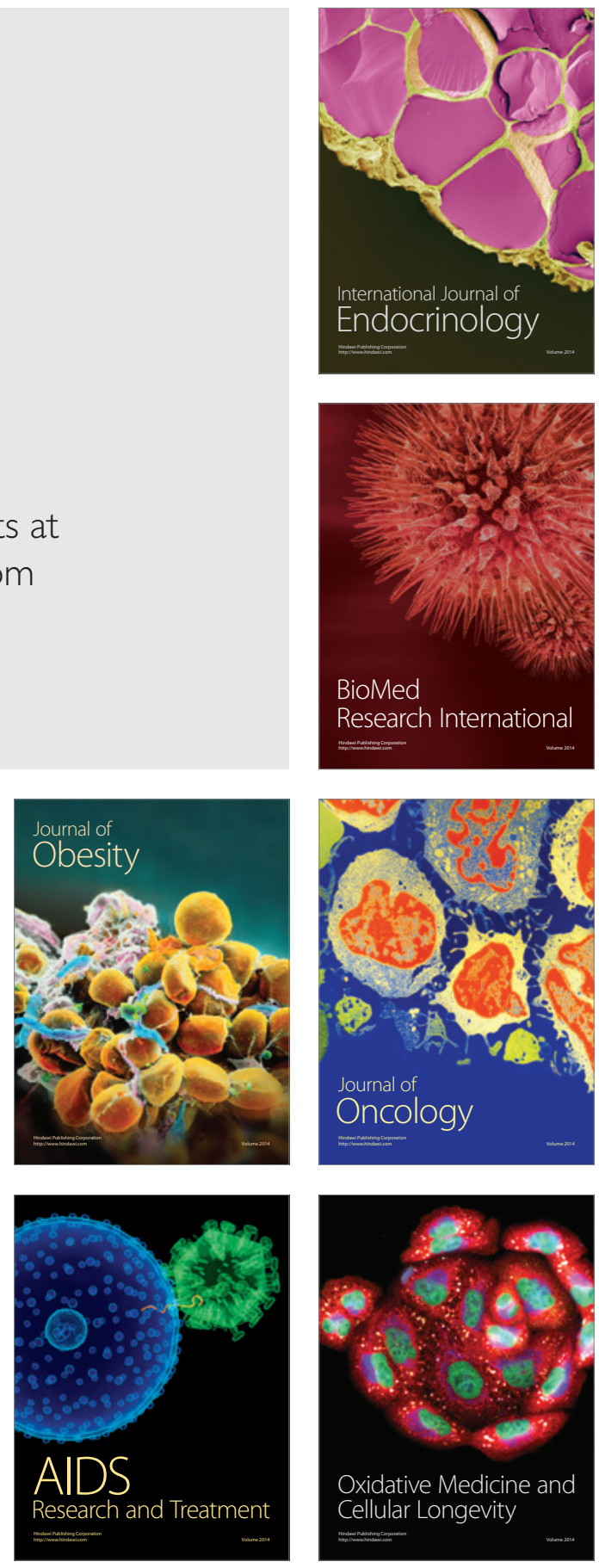